Peer-Reviewed Article

ISSN: 2162-3104 Print/ ISSN: 2166-3750 Online

Volume 5, Issue 4 (2015), pp. 447-458

(C) Journal of International Students

http://jistudents.org/

\title{
The Forgotten Half: Understanding the Unique Needs of International Student Partners
}

\author{
Danni Lei (Master's Student) \\ Jon D. Woodend (Doctoral Student) \\ Sarah K. Nutter (Doctoral Student) \\ Alyssa R. Ryan (Master's Student) \\ Sharon L. Cairns, PhD \\ University of Calgary (Canada)
}

\begin{abstract}
With the increasing enrollment of international students in North American universities, the need to support the adjustment of international students has also increased. One factor consistently identified as essential to successful student adjustment is having a strong support network, including familial support. Previous research investigating the needs of international students' partners is limited and has suggested that partners may face greater barriers to adjustment than international students. The current study was conducted to better understand the needs of partners as well as potential barriers they face when attempting to access services. Although limited by sample size, the results suggested that partners are interested in increased support in helping their transition to local living and mainstream culture.
\end{abstract}

Keywords: international students; international spouses; needs assessment; cross-cultural adjustment

Amid the recent trend of international movement and globalization, a growing number of students have crossed national boundaries to seek education, with many attending Western universities (Institute of International Education, 2009). At the same time, post-secondary institutions across Canada have pushed to increase the enrolment of international students. Consequently, there has been a push for universities to support students' adjustment (Institute of International Education, 2009). Upon arrival, students are immersed within a new culture and are forced to navigate a new cultural context while retaining a sense of their heritage, a process known as acculturation (Li \& Gasser, 2005).

Research investigating the cross-cultural adjustment of international students has identified challenges in acculturating ( $\mathrm{Li} \&$ Gasser, 2005). The influence of cultural adjustment on international students' often results in difficulties including language barriers, lack of support, and lack of familiarity with the school system (Andrade, 2006). These difficulties may lead to persistent feelings of isolation, inadequacy, depression, and anxiety (Rosenthal, Russell, \& 
Thomson, 2007). One factor consistently identified as essential to successful student adjustment is having a strong support network, including familial support (Kwon, 2009). With an increasing number of partners accompanying international students to Western, English-speaking countries it is important to understand the unique needs and well-being of these partners due to the potential impact on international student adjustment (Martens \& Grant, 2008).

\section{Literature Review}

The presence of a partner in a new country may lessen the effects of stressful events for international students and provide a sense of social connectedness (Martens \& Grant, 2008). However, research on the experiences of international students' partners is limited. Previous research has stressed that students' accompanying partners may face even greater barriers to adjustment than the student (Martens \& Grant, 2008). Transitioning to a new country disrupts established social support networks and presents the challenge of developing new ones (Misra, Crist, \& Burant, 2003). Such changes may be especially stressful for partners and can cause difficulties in adjustment due to family responsibilities, social isolation, socio-political constraints, and changes in social and/or work status (Copeland \& Norell, 2002; Zhang, Smith, Swisher, Fu, \& Fogarty, 2011). Unlike international students who are immersed in academic culture, partners may have limited opportunities to interact with others and to learn about the host culture (Cho, Lee, \& Jezewski, 2005). With these challenges in mind, partners have begun to believe that academic institutions have a responsibility to provide them with support (Teshome \& Osei-Kofi, 2011).

Research has suggested that student partners experience unique difficulties such as the inability to seek employment due to visa type, loss of established roles and lifestyles, and lack of social connectedness (Copeland \& Norrell, 2002; Kim, 2006). Such difficulties may impact student partners' emotional and mental well-being, leading to feelings of invisibility and marginalization (Teshome \& Osei-Kofi, 2011). Understanding their needs is essential to providing appropriate support and fostering a sense of belonging. A previous needs assessment on female spouses of international students identified three important needs: (a) the opportunity to take part in professional development opportunities through the university, (b) the availability of adequate childcare in order to participate in programs, and (c) the opportunity to become involved in the development and delivery of programs aimed towards student partners (Martens \& Grant, 2008). Further, research conducted on an existing program suggested that partners viewed such programs as a source of support (Teshome \& Osei-Kofi, 2011). However, some partners felt English language proficiency was not taken into account, highlighting the importance of developing programs based on specific needs and specific contexts of the student partners (Teshome \& Osei-Kofi, 2011).

\section{The Current Study}

Although previous research has been conducted investigating the experiences and needs of partners of international students (e.g. Martens \& Grant, 2008; Zhang et al., 2011), further research is necessary to establish a foundation of knowledge to inform program development. Such an understanding can inform university programming that aims to provide support for this population, which highlights the necessity of an evaluation of the circumstances, needs and requirements of international student partners for successful adjustment. In addition, the majority of the research on partners of international students has focused only on female

September/October 2015 http://jistudents.org $\quad$ Volume 5 •Issue 4


partners. Further research needs to be conducted in order to understand the needs of both female and male partners.

The current study was conducted at a large Canadian university in partnership with the university's international student center's director, who requested the researchers investigate ways in which the center's preexisting program could be improved in order to boost attendance and participation. The director identified previous attempts to run a partner support program at the university with varying success. Specifically, while few participants attended the scheduled events, the director continued to hear from students, partners, other university staff, and national conferences that there was a need for such services.

In response to this request, a needs assessment was conducted via online survey in order to help identify the needs of international students' partners and gaps in pre-existing services (Royse, Thyer, \& Padgett, 2010). A generally accepted practice in conducting needs assessments is to construct a logic model, which may serve as a theoretical framework to guide the study. Specifically, it identifies the various components (i.e., resources) that go into the short-term, mid-term, and long-term goals, and the desired outcomes of the program (Royse et al., 2010). The logic model for this study was developed in consultation with the direct stakeholders, including the director of the international services office as well as referencing previous research. See Table 1 for the detailed logic model. This logic model provided the specific research questions used in this study as well as informing the analyses and discussion.

\section{Research Method}

A mixed-method was chosen to best address the overarching evaluation questions. Specifically there were four research questions in the current study;

1. How do social connection, acculturation, and English language usage relate to current life satisfaction in partners of international students?

2. What services do partners identify as being potentially helpful and why?

3. What barriers do partners experience? and

4. What might help enable partners to access services?

\section{Participants}

Due to difficulty with directly contacting partners of international students, the survey was distributed to the international students themselves. Making contact with international students allowed for an examination of the demographics of the international students with partners. A self-selected sample of 39 international students ( 24 females, 11 males, 4 undisclosed) responded to the survey invitation. The majority of international students were at the graduate level (25 graduate students, 10 undergraduate students, 4 undisclosed). Nineteen international students indicated having partners, fifteen of who were currently lived together. Three of these fifteen students reported having children.

Although 15 international students (14 graduates, 1 undergraduate) indicated that their partner was currently living with them, only 11 partners ( 7 males, 4 females) chose to participate in the study. Although 11 partners completed the demographic portion of the survey, only 9 partners ( 6 females, 3 males) elected to continue with the survey and complete the remaining quantitative and qualitative sections. All of the 9 partners fully answered all questions. 
Table 1: Logic Model for Constructing International Student Partner Support Program

\begin{tabular}{|c|c|c|c|c|c|}
\hline Program & Program & Output & \multicolumn{3}{|c|}{ Desired Outcomes } \\
\hline & & & $\begin{array}{l}\text { Short- } \\
\text { Term }\end{array}$ & Intermediate & Long-term \\
\hline $\begin{array}{c}\text { Staff } \\
\text { (Director and } \\
\text { advisor) }\end{array}$ & $\begin{array}{l}\text { Orientation } \\
\text { (Twice } \\
\text { yearly) }\end{array}$ & $\begin{array}{c}\text { Orientation } \\
\text { (Record number } \\
\text { of attendees) }\end{array}$ & $\begin{array}{c}\text { Increase } \\
\text { familiarity } \\
\text { with local } \\
\text { culture }\end{array}$ & $\begin{array}{c}\text { Increase } \\
\text { campus and } \\
\text { community } \\
\text { involvement }\end{array}$ & $\begin{array}{l}\text { Increase social } \\
\text { inter- } \\
\text { connectedness }\end{array}$ \\
\hline $\begin{array}{c}\text { Funding } \\
\text { (Internationa } \\
\text { l Students }\end{array}$ & $\begin{array}{l}\text { Monthly } \\
\text { meetings }\end{array}$ & $\begin{array}{c}\text { Meetings } \\
\text { (Record number } \\
\text { of attendees) }\end{array}$ & $\begin{array}{c}\text { Increase } \\
\text { awareness }\end{array}$ & $\begin{array}{c}\text { Mediate } \\
\text { concerns with }\end{array}$ & $\begin{array}{c}\text { Facilitate } \\
\text { acculturation }\end{array}$ \\
\hline $\begin{array}{c}\text { Services } \\
\text { central } \\
\text { operating) }\end{array}$ & $\begin{array}{c}\text { Email } \\
(\text { All/ } \\
\text { ListServ) }\end{array}$ & $\begin{array}{c}\text { Advising } \\
\text { (Record number }\end{array}$ & $\begin{array}{c}\text { of } \\
\text { concrete } \\
\text { resources }\end{array}$ & $\begin{array}{l}\text { culture-shock } \\
\text { and transition }\end{array}$ & $\begin{array}{l}\text { Increase well- } \\
\text { being and } \\
\text { academic }\end{array}$ \\
\hline $\begin{array}{l}\text { Ideas } \\
\text { (Other post- } \\
\text { secondarv }\end{array}$ & $\begin{array}{l}\text { Individual } \\
\text { advising }\end{array}$ & $\begin{array}{c}\text { of individual } \\
\text { meetings) } \\
\text { Activities }\end{array}$ & $\begin{array}{l}\text { Increase } \\
\text { social } \\
\text { network }\end{array}$ & $\begin{array}{c}\text { Reduce } \\
\text { language } \\
\text { barriers and } \\
\text { increase }\end{array}$ & $\begin{array}{l}\text { performance of } \\
\text { international } \\
\text { students }\end{array}$ \\
\hline institutions) & $\begin{array}{c}\text { Social } \\
\text { events } \\
\text { Provide } \\
\text { childcare at } \\
\text { meetings }\end{array}$ & $\begin{array}{c}\text { (Record number } \\
\text { of attendees) }\end{array}$ & $\begin{array}{l}\text { and } \\
\text { support }\end{array}$ & English skills & $\begin{array}{c}\text { Disseminate } \\
\text { knowledge across } \\
\text { Canadian post- } \\
\text { secondary } \\
\text { institutions }\end{array}$ \\
\hline
\end{tabular}

\section{Instrumentation}

Bicultural identity. The Bicultural Self-Efficacy Scale (David, Okazaki, \& Saw, 2009) is a 26-item measure, which assesses an individual's perceived bicultural self-efficacy. Items are rated in a Likert type response format, with the scale ranging from 1 (strongly disagree) to 9 (strongly agree), with higher scores indicating a greater degree of perceived bicultural selfefficacy. The scale consists of six subscales; social groundedness, communication ability, positive attitudes, knowledge, role repertoire, and bicultural beliefs. An example item is, "I can communicate my ideas effectively to both mainstream Canadians and people from the same heritage culture as myself." Internal consistency for the subscales range from good to excellent, $\alpha=.69$ to $\alpha=.91$, and two-week test-retest reliabilities for the subscales range from fair to good, $r=.58$ to $r=.78$. The Bicultural Self-Efficacy Scale has been established as an acceptable tool for measuring acculturation and is positively associated with psychological adjustment (Chen, Benet-Martinez, Wu, Lam, \& Bond, 2013). 
English language usage. The English Language Acculturation Scale (Salamonson, Everett, Koch, Andrew, \& Davidson, 2008) is a five-item measure, which was designed to serve as an indicator of an individual's English language usage (Salamonson, Attwood, Everett, Weavers, \& Glew, 2013). Items are rated in a Likert type response format, with the scale ranging from 1 (only non-English language(s)) to 5 (only English) with higher scores indicating greater English language usage. An example item is, "what language(s) do you speak?" Internal consistency for the English Language Acculturation Scale was excellent at $\alpha=.94$. It was also found to have a moderate and significant correlation with length of stay in host country, $r=.53$ (Salamonson et al., 2013).

Social connectedness. The Social Connectedness Scale (Lee \& Robbins, 1995) is an eight-item measure assessing the degree to which individuals feel socially disconnected and detached. Items are rated in a Likert type response format, with the scale ranging from 1 (strongly disagree) to 6 (strongly agree) with higher scores indicating greater feelings of social disconnectedness. An example item is, "I feel disconnected from the world around me." Internal consistency for the Social Connectedness Scale was excellent at $\alpha=.91$, and two-week test-retest reliability was also excellent at $r=.96$.

Satisfaction with life. The Temporal Satisfaction with Life Scale (Pavot, Diener, \& Suh, 1998) is a 15-item measure assessing an individual's past, present and anticipated future life satisfaction and subjective well-being. Items are rated in a Likert type response format, with the scale ranging from 1 (strongly disagree) to 7 (strongly agree) with higher scores indicating greater satisfaction with life. An example item is, "I would change nothing about my current life." The Temporal Satisfaction with Life Scale had an excellent internal consistency at $\alpha=.92$, and a very good four-week test-retest reliability of $r=.83$. For the purposes of the current research, only the five items from the current life satisfaction subscale were used.

Qualitative survey. Directed and summative content analysis was used throughout the qualitative portion of the survey. Directed content analysis allows researchers to use preexisting literature to inform choice options for each question or theme examined (Hsieh \& Shannon, 2005); while summative content analysis counts the number of times each choice option is identified by participants (Hsieh \& Shannon, 2005; Lichtman, 2013). The qualitative portion of the survey was divided into three sections, and consisted of six questions. Each question included potential answers gathered from the literature and from consulting with the International Student Centre, in order to ease answering in light of potential language barriers. Participants were also able to include their own unique answers. The first section of questions sought to identify services regarded as helpful by partners; accordingly, participants were asked about programs and services they had previously accessed, and how these services had helped them. Next, participants were asked about programs and services they had not accessed, and how these services could be helpful to them in the future. Finally, participants were asked about barriers to accessing services and what would potentially assist them in accessing services.

\section{Procedure}

International student participants were recruited through the international student email newsletter, the Graduate Student Association newsletter, and posters placed around the university campus. Recruitment and data collection took place between January and April 2014. 
After providing demographic information, student participants indicated whether or not they have a partner who is currently living with them. If students indicated they do have a partner, the survey requested the student to have their partner complete the rest of the survey. Partners were then invited to complete the remaining demographic questions, quantitative measures, and qualitative questions. Full completion of the survey took approximately 30 to 45 minutes.

\section{Results}

\section{Demographics}

Partners had an average age of 32.82 years $(S D=8.97)$, had been in Canada an average 69.56 months $(S D=44.73)$, and had been in a relationship with their student partner for an average of 42.00 months $(S D=51.60)$.

\section{Table 2: Home Countries of Partners of International Students}

\begin{tabular}{ll}
\hline \multicolumn{1}{c}{ Country } & $\mathrm{n}$ \\
\hline Canada & 2 \\
China & 1 \\
Ecuador & 2 \\
Iran & 1 \\
Israel & 1 \\
Mexico & 2 \\
Slovakia & 1 \\
\hline
\end{tabular}

Partners were from a variety of home countries (see Table 2) and selfreported as being fluent in a variety of languages (see Table 3). Two partners identified as Canadian-born. Accordingly, their lengths of time in Canada were excluded from the average. However, their remaining responses were included in the aggregate data because they also represent partners of international students.

\section{Table 3: Self-reported Fluent Languages by Partners}

\begin{tabular}{ll}
\hline Language & $\mathrm{n}$ \\
\hline Arabic & 1 \\
Czech & 1 \\
English & 7 \\
Farsi & 1 \\
Hebrew & 1 \\
Russian & 1 \\
Slovak & 1 \\
Spanish & 3 \\
\hline
\end{tabular}

Due to the lack of current demographic information about international students who come to university with partners, an additional analysis was conducted to investigate the unsubstantiated assumption that graduate students are more likely than undergraduate students to have a partner who accompanies them. To do this, a chi square analysis, which consists of an odds ratio, was conducted to compare the number of graduate international students with partners to undergraduate international students with partners. The chi square analysis was significant, $\chi^{2}(1)=6.43, p=.01$, with the odds ratio suggesting that, in the current sample, graduate students were 23 times more likely to have a partner than undergraduate students.

\section{Quantitative Questionnaires}

Given that only nine partners completed the quantitative and qualitative portion of the survey, descriptive statistics were used to examine scores on the quantitative questionnaires (Table 4). Participants' scores for degree of acculturation and current life satisfaction were high, which indicated that participants were generally satisfied with their current life and believed they were well-adjusted to navigating Canadian culture. Scores for English language acculturation indicated that participants equally use both English and non-English languages in day-to-day life. Despite these scores, scores for social connectedness were low, indicating that participants felt 
socially isolated. Correlational analyses revealed that higher reported English language acculturation was associated with both higher reports of social connection and current life satisfaction.

Table 4: Descriptive Statistics for Partner Quantitative Measures

\begin{tabular}{lccc}
\hline \multicolumn{1}{c}{ Variable } & Range & $M$ & $S D$ \\
\hline Social connectedness & $8-38$ & 15.89 & 9.46 \\
Acculturation & $136-230$ & 183.56 & 35.31 \\
English language usage & $5-25$ & 14 & 6.18 \\
Current life satisfaction & $11-35$ & 25 & 8.12 \\
\hline
\end{tabular}

As well, lower reports of perceived social connectedness were associated with lower reports of current life satisfaction. See Table 5 for correlation coefficients.

Table 5: Intercorrelations among the Quantitative Measures

\begin{tabular}{lllll}
\hline Variable & Acculturation & English Usage & $\begin{array}{l}\text { Social } \\
\text { Connectedness }\end{array}$ & $\begin{array}{l}\text { Current Life } \\
\text { Satisfaction }\end{array}$ \\
\hline Acculturation & - & 0.64 & -0.58 & -0.53 \\
English Usage & - & $-0.71^{*}$ & $0.71^{*}$ \\
Social Connectedness & & - & $-0.80^{* *}$ \\
Current Life Satisfaction & & & - & - \\
\hline
\end{tabular}

Note. $* p<.05 ; * * p<.01$

\section{Services Identified as being Potentially Helpful}

When asked what programs and services partners have used in the past, five participants indicated that obtaining information about the transit and healthcare systems was helpful. Further, three participants indicated having volunteer opportunities, information about day-today activities, and receiving help getting a job in Canada were helpful services. Finally, two participants felt that having English classes and professional development workshops had been helpful. See Table 6 for frequency counts of all items included in the program and service list.

Participants also indicated how these programs and services had helped them. Of the participants who had accessed services, five indicated that these services had helped them to become more comfortable with Canadian culture. Four participants indicated that services reduced loneliness, reduced stress, and helped them to meet new people. Three participants indicated these services helped them to navigate the city, to reduce financial strain, and to improve English abilities.

When asked what programs and services partners have not used in the past, but which they feel would be helpful, four participants indicated information about the healthcare system, having social events (with other international students/partners as well as mixed events with Canadian students/partners), and professional development workshops would be helpful. Three participants identified help getting a job and English classes would be beneficial and two participants indicated they would have liked to receive information about the transit system.

Finally, partners were asked how programs and services they had not accessed could be helpful to them. Five participants indicated that these services could help to reduce loneliness and improve English. Three indicated these services would be helpful to increase time with spouse, help with the completion of necessary tasks (e.g., grocery shopping), help participants 
meet people, help participants become more comfortable in Canadian culture, and help learn more about Canadian culture.

Table 6: Services Identified as Previously Helpful or Potentially Helpful by Partners

\begin{tabular}{lcc}
\hline & Previously & Potentially \\
& Helpful & Helpful \\
\cline { 2 - 3 } Programs/Services & $n$ & $n$ \\
\hline Information about transit system & 5 & 4 \\
Information about health care system & 5 & 4 \\
Information about day-to-day activities & 3 & 4 \\
Volunteer opportunities & 3 & 4 \\
Help getting a job & 3 & 3 \\
English classes & 2 & 3 \\
Professional development workshops & 2 & 2 \\
Cooking classes & 1 & 1 \\
First aid/CPR & 1 & 1 \\
Programs for children & 1 & 1 \\
Information and connections to volunteer opportunities & 1 & 1 \\
Childcare & 0 & 1 \\
Social events with international students & 0 & 1 \\
Mixed social events with Canadian students & 0 & 0 \\
Computer training & 0 & 0 \\
Exercise classes & 0 & \\
\hline
\end{tabular}

\section{Barriers Identified to Accessing Services}

Participants were asked about the barriers they have experienced in accessing needed services. Three participants indicated not understanding spoken English and having trouble speaking English as significant barriers, as well as not knowing where these services can be accessed. Two of the three participants with children indicated that not having access to childcare and the cost of childcare as barriers to accessing potentially beneficial services. Difficulty understanding the transit system and having time constraints were also both identified by one participant as barriers.

\section{Aids Identified as Enabling Access to Services}

Finally, participants were asked what might help to enable them in accessing needed programs and services. In contrast to the responses on the previous qualitative questions, only one or two participants endorsed each of the items for this question. Two participants indicated that having access to a translator or information in their primary language would be helpful, and that they would also benefit from the aid of a mentor who could help them become more familiar with how things work in Canada. In addition, two participants indicated that they would be interested in volunteer opportunities to help plan services for other partners at the university. Finally, the two participants who identified as having children specified that having childcare would be helpful. 


\section{Discussion}

The purpose of the current study was to identify the unique needs of partners of international students, to identify the barriers partners experience when attempting to access needed services, and aids that may enable them to access needed services in the future. In line with the findings of research conducted by Martens and Grant (2008), the results suggest that partner participants want: (a) to be involved in professional development, (b) aid with accessing childcare, (c) to participate in programming for partners of international students, and (d) to improve their English abilities.

Partner participants in this needs assessment identified that learning more about Canadian culture and becoming more comfortable with navigating Canadian culture would be helpful and desired. Previous research has suggested that the longer the time spent in Canada, the less likely partners are to express the need for opportunities to increase Canadian cultural awareness (Copeland \& Norell, 2002). In our sample, however, even though partners reported being in Canada for over a year on average, partners still reported a desire to increase their comfort with Canadian culture. This may suggest that partners experience a lack of opportunities or resources to learn about Canadian culture.

In both the quantitative and qualitative portions of the survey partner participants reported experiencing low social connectedness. More than half of the participants endorsed "reduce loneliness" as a reason for why services would be helpful. This suggests that partners do experience loneliness and feelings of isolation, and also recognize that reducing this loneliness could improve their overall day-to-day experience. This was supported in the current study as partners who indicated feeling more socially disconnected also reported lower life satisfaction. These findings are consistent with the position of Misra and colleagues (2003), who asserted that people transitioning to a new country face the challenge of developing new social networks. For partners of international students, this may be more difficult because they are often isolated due to a lack of involvement in education, work, or the community (Copeland \& Norell, 2002; Teshome \& Osei-Kofi, 2012).

Concerning barriers to accessing services, the most endorsed barriers that partner participants identified were related to English skills as well as not knowing where services are provided. With regard to English skills, this finding contrasts the result from the English Language Acculturation Scale, which suggested that participants generally use English about half the time and possibly indicates some proficiency. A potential explanation for this discrepancy may be that, although participants find they use English, they still wish to improve their skill level, which may help increase feelings of adjustment as well as allow partners to interact with greater ease with individuals from mainstream culture (Yeh \& Inose, 2003). The current study did find that increased English language usage was related to increased life satisfaction and social connectedness. Language acquisition has previously been identified as critical to successful adjustment for international student spouses (Martens \& Grant, 2008). This is consistent with the findings from the current study, which suggest that participants view English classes as potentially helpful and that difficulty with understanding spoken English is a potential barrier.

A unique finding was that the majority of graduate students were female with male partners. Previous research investigating the needs of international students' partners has been conducted only with female partners (Martens \& Grant, 2008; Teshome \& Osei-Kofi, 2012). The results of the current study may suggest that the number of female international students 
with male partners is increasing or has been higher than previously assumed. The potentially unique needs of male partners may be important to explore in future research. Finally, two partner participants indicated originating from Canada, which highlights an incorrect assumption that international student partners are only foreign nationals. These Canadian-born partners may have different needs and may possess different resources than foreign-born partners, which may have impacted the average scores on self-reported social connectedness found in this study.

\section{Limitations and Directions for Future Research}

Given the small sample size in this study, it is clear that follow up research needs to be conducted with a larger and more diverse sample in order to better understand the unique needs of international student partners. The experience of the nine partners who responded to the survey may not be generalizable to the experiences and needs of other partners of international students. Future research should investigate further the demographics of the international students and their partners. Specifically, it would be helpful to identify if students and their partners originate from the same or different countries as mixed groups may have unique needs.

In addition, it is important to acknowledge that the current study took place in the Canadian context, which may be quite different in terms of services rendered and service objectives, when compared to the context in the United States. As such, further research is needed within the Canadian context, as well as within the United States, to provide a stronger foundation for studies on international student partners.

English proficiency was required to understand and complete the survey. Although 15 student participants identified having a partner in Canada only nine partners fully completed the survey. A potential explanation for this discrepancy may be that the responses gathered represent partners with greater English abilities, which would be consistent with previous research (Salamonson et al., 2008). It is also possible that the partners who completed the survey lack the language skills to further express their experiences. This may have contributed to the fact that few participants wrote responses outside of those provided in the qualitative questions. This is important when considering the key findings as it is unknown to what degree the partners were able to fully comprehend the questions being presented and if their responses are an appropriate reflection of their experience. Despite these limitations, the current study adds unique findings to the limited literature investigating the needs of international student partners.

As a result of the low response to an online survey, it is recommended that future research utilize alternative data collection methods, such as focus groups. In addition, a previous needs assessment conducted by Martens and Grant (2008) offered translated surveys, which may aid in data collection as well as provide partners with reduced English language ability with the increased opportunity to engage in the survey.

\section{Conclusion}

This needs assessment had findings that will be valuable to explore in future research. More specifically, the results of the current research suggest that partners of international students primarily struggle with social isolation and may benefit from the opportunity to take English classes, engage in conversational English clubs, and volunteer opportunities in addition to receiving information about the local healthcare and transit systems. Affordable childcare is a concern for the partners with children. Further, the results tentatively suggest that the proportion

September/October $2015 \quad$ http://jistudents.org $\quad$ Volume 5 •Issue 4


of male partners of female international students may be increasing or higher than previously expected. By exploring the unique needs of both male and female partners of international students, researchers and service providers may be better equip to serve international students and their partners and to assist them in successfully integrating into the campus community and society at-large.

\section{REFERENCES}

Andrade, M. S. (2006). International students in English-speaking universities: Adjustment factors. Journal of Research in International Education, 5, 131-154. doi:10.1177/1475240906065589

Chen, S. X., Benet-Martinez, V., Wu, W. C., Lam, B. C., \& Bond, M. H. (2013). The role of dialectical self and bicultural identity integration in psychological adjustment. Journal of Personality, 81, 61-75. doi:10.1111/j.1467-6494.2012.00791.x

Cho, K., Lee, J., \& Jezewski, M. (2005). Korean women living in the United States as student wives. Health Care for Women International, 26, 897-915. doi:10.1080/07399330500301838

Copeland, A. P., \& Norell, S. K. (2002). Spousal adjustment on international assignments: The role of social support. International Journal of Intercultural Relations, 26, 255-272. doi:10.1016/S0147-1767(02)00003-2

David, E. J., Okazaki, S., \& Saw, A. (2009). Bicultural self-efficacy among college students: Initial scale development and mental health correlates. Journal of Counseling Psychology, 56, 211-226. doi:10.1037/a0015419

Hsieh, H., \& Shannon, S. (2005). Three approaches to qualitative content analysis. Qualitative Health Research, 15, 1277-1288. doi:10.1177/104973230527668

Institute of International Education (2009). Open doors report 2007/2008: International students in the U.S. (Report on International Educational Exchange). New York, NY: IIE Network: Retrieved from http://opendoors.iienetwork.org

Kim, M. (2006). Forced into unpaid carework: International students' wives in the United States. In M. K. Zimmerman, J. S. Litt, \& C. E. Bose (Eds.), Global dimensions of carework and gender (pp. 163-175). Palo Alto, CA: Stanford University Press.

Kwon, Y. (2009). Factors affecting international students' transition to higher education institutions in the United States: From the perspective of office of international students. College Student Journal, 43, 1020-1036.

Lee, R. M., \& Robbins, S. B. (1995). Measuring belongingness: The social connectedness and the social assurance scales. Journal of Counseling Psychology, 42, 232-241. doi:10.1037//0022-0167.42.2.232

Li, A., \& Gasser, M. B. (2005). Predicting Asian international students' sociocultural adjustment: A test of two mediation models. International Journal of Intercultural Relations, 29, 561-576. doi:10.1016/j.ijintrel.2005.06.003

Lichtman, M. (2013). Qualitative research in education: A user's guide (3rd ed.). Thousand Oaks, CA: Sage.

Martens, V. P., \& Grant, P. R. (2008). A needs assessment of international students' wives. Journal of Studies in International Education, 12, 56-75. doi:10.1177/102831530 6293547 
Misra, R., Crist, T., \& Burant, C. (2003). Relationships among life stress, social support, academic stressors, and reactions to stressors of international students in the United States. International Journal of Stress Management, 10, 137-157. doi:10.1037/10725245.10.2.137

Pavot, W., Diener, E., \& Suh, E. (1998). The temporal satisfaction with life scale. Journal of Personality Assessment, 70, 340-354. doi:10.1207/s15327752jpa7002_11

Rosenthal, D. A., Russell, J., \& Thomson, G. (2007). Social connectedness among international students at an Australian university. Social Indicators Research, 84, 71-82. doi:10.1007/s11205-006-9075-1

Royse, D., Thyer, B. A., \& Padgett, D. K. (2010). Program evaluation: An introduction (5th ed.). Belmont, CA: Wadsworth.

Salamonson, Y., Attwood, N., Everett, B., Weaver, R., \& Glew, P. (2013). Psychometric testing of the English Language Acculturation Scale in first-year nursing students. Journal of Advanced Nursing, 69, 2309-2316. doi:10.1111/jan.12098

Salamonson, Y., Everett, B., Koch, J., Andrew, S., \& Davidson, P. M. (2008). English-language acculturation predicts academic performance in nursing students who speak English as a second language. Research in Nursing \& Health, 31, 86-94. doi:10.1002/nur.20224

Teshome, Y., \& Osei-Kofi, N. (2011). Critical issues in international education: Narratives of spouses of international students. Journal of Studies in International Education, 16, 6274. doi:10.1177/ 1028315311403486

Yeh, C. J., \& Inose, M. (2003). International students' reported English fluency, social support satisfaction, and social connectedness as predictors of acculturative stress. Counselling Psychology Quarterly, 16, 15-28. doi:10.1080/0951507031000114058

Zhang, J., Smith, S., Swisher, M., Fu, D., \& Fogarty, K. (2011). Gender role disruption and marital satisfaction among wives of Chinese international students in the United States. Journal of Comparative Family Studies, 42, 523-542.

\section{AUTHORS}

DANNI LEI, BSc, is an MSc Counselling Psychology student at the University of Calgary. Danni's research interests include immigrant transitions, career development, multiculturalism, and social justice. Email: dlei@ucalgary.ca

JON WOODEND, MSc, is a PhD Counselling Psychology student at the University of Calgary. Jon's research interests include international career transitions, multiculturalism, immigration, and social justice. Email: jdwooden@ucalgary.ca

SARAH NUTTER, MSc, is a PhD counselling psychology student at the University of Calgary. Sarah's research interests include weight bias and its sociocultural correlates, and social justice. Email: snutter@ucalgary.ca

ALYSSA RYAN, BA, is an MSc Counselling Psychology student at the University of Calgary. Alyssa's research interests include resiliency, individuals and families with child welfare involvement, and social justice. Email: arryan@ucalgary.ca

SHARON CAIRNS, PhD, is an Associate Professor in Counselling Psychology at the University of Calgary. Dr. Cairns research interests include post-secondary counselling, student mental health, and resiliency. Email: scairns@ucalgary.ca

$* * *$

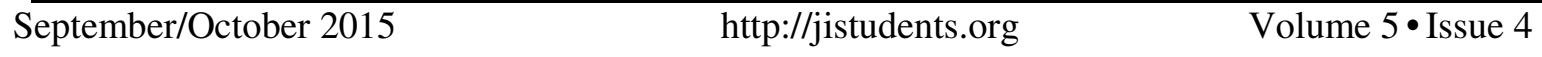

